\title{
NUTRICIÓN
}

\section{Perfil lipídico en una cohorte de pacientes HIV positivos con tratamiento antirretroviral del Programa Regional de Control VIH- SIDA de la VII Región Sanitaria de Itapúa}

\author{
Celso Obdulio Mora Rojas ${ }^{1}$, Lucía Margarita Gómez Fretes ${ }^{1}$, Mirta \\ Arapayú ${ }^{2}$, Celina Mabel Llano Vanni²
}

\begin{abstract}
Resumen
Introducción: Numerosas investigaciones demuestran que existe alteración del metabolismo lipídico en pacientes con VIH/SIDA, caracterizada por un aumento en la concentración de triglicéridos y la disminución de las lipoproteínas de alta y baja densidad y del colesterol total. La dislipidemia en personas VIH/ SIDA depende de la supresión viral en el momento del estudio, de la respuesta al agente antirretroviral específico que se relaciona con la susceptibilidad genética, además de otros factores entre los cuales se encuentra el empleo de medicamentos, el peso y el estilo de vida. Los pacientes que conviven con esta infección tienen por esta razón un riesgo incrementado de accidente cardiovascular y diabetes. El objetivo de este estudio es determinar si existen diferencias en el perfil lipídico en una cohorte de pacientes que reciben esquemas de tratamientos diferentes en el programa Regional de Control VIHSIDA, de la VII Región Sanitaria de Itapúa, y esas diferencias sí se encuentran en la cohorte estudiada. Es menester realizar control periódico del perfil lipídico en estos grupos de pacientes, pues ello contribuirá a un mejor seguimiento del estado de salud y una intensificación en la prevención de accidentes cardiovasculares en los pacientes que conviven con VIH/SIDA, y que están en tratamiento con antirretrovirales.
\end{abstract}

Objetivo: Determinar diferencias en el perfil lipídico en una cohorte de pacientes del programa Regional de Control VIH-SIDA, de la VII Región Sanitaria de Itapúa, que reciben esquemas de tratamientos diferentes.

Material y Método: Diseño: Cohortes prospectivo. Descripción del lugar de investigación: Laboratorio de la Facultad de Medicina - UNI. Terapia antirretroviral: Variable categórica nominal.

Grupo 1: con Azt - 3TC - la combinación Lopinavir-Ritonadir. Grupo 2: con

1. Universidad Nacional de Asunción, Facultad de Ciencias Químicas, Paraguay.

2. Universidad Nacional de Itapúa, Facultad de Medicina, Paraguay.

E-mail: cmoraroj@gmail.com

DOI: $10.26885 /$ rcei.foro.2019.231

Trabajo publicado en acceso abierto bajo Licencia Creative Commons. 
tratamiento AZT + 3TC + Efavirenz .

Resultados: La presente investigación verifica, que existen diferencias significativas aplicando las Pruebas de Levene y de la $t$, entre los valores de colesterol, triglicéridos, LDL y VLDL entre los pacientes que reciben el Tratamiento 1 que incluye fármacos inhibidores de la proteasa y los que reciben el Tratamiento 2, que no incluyen fármacos inhibidores de la proteasa.

Estos resultados coinciden con los referidos en la literatura. Desde ningún punto de vista se está juzgando la efectividad de los tratamientos, ni tampoco la causalidad del tratamiento como responsable de las alteraciones del perfil lipídico; sí que existe asociación entre ellas.

Por otro lado cabe mencionar, que esta asociación conlleva a que los médicos tratantes, evalúen periódicamente el perfil lipídico de sus pacientes, ya que las alteraciones metabólicas de los lípidos están asociados a problemas cadiometabólicos, que podrían ser evitados o controlados.

Conclusiones: Se encuentra que existe asociación entre el uso de los inhibidores de la proteasa como componentes de los TARV y las alteraciones del perfil metabólico lipídico. Por lo tanto es necesario incluir el control periódico el perfil lipídico de los pacientes tratados. La hiperlipemia es la complicación más frecuente del TAR con inhibidores de proteasa. Actualmente, también se han reportado casos de enfermedad prematura coronaria o complicaciones vasculares en los pacientes tratados con éstos, que podrían ser prevenidos mediante el monitoreo continuo del metabolismo lipídico.

Palabras clave: perfil lipídico, antirretrovirales, tratamiento.

\section{RefERENCIAS}

Constans, J., Pellegrin. J. L., Peuchant, E. (1994). Plasma lipids in HIVinfected patients: a prospective in 95 patients. Eur J ClinInvest, 24, 416-420.

Gallin, J. I, Kaye, D., O'Leary, W. M. (1969). Serum lipids in infection. N Engl J Med, 281,1081-1086.

Kotler, D. P. (2008). HIV and Antiretroviral Therapy: Lipid Abnormalities and Associated Cardiovascular Risk in HIV-Infected Patients. I AcquirlmmuneDeficSyndr, 49(2), S279-S85.

Kotler, D. P. (2008). HIV and antiretroviral therapy: lipid abnormalities and associated cardiovascular risk in HIV-infected patients. J AcquirlmmuneDeficSyndr, 49(2), S279-S85.

Vacarezza, C., Vázquez, P. R., Larriera, S. (2003). Alteraciones del metabolismo lipídico en pacientes infectados por VIH. Revista Médica Uruguaya, 19(1), 45-52. 